\title{
Self-Adjustment Process of Flow Pathway in a Narrow Curved Channel
}

\author{
Hiroshi Hayakawa ${ }^{1, *}$, Tomonori $\mathrm{Kitao}^{2}$, and Nobuo Sato $^{3}$ \\ ${ }^{1}$ Professor, Kitami Institute of Technology, 165 koen-cho Kitami Hokkaido, Japan \\ ${ }^{2}$ Engineer, Takenaka Civil Engineering \& Construction Co., Ltd., Tokyo, Japan \\ ${ }^{3}$ Engineer, Sumitomo Mitsui Construction Co., Ltd., Tokyo, Japan
}

\begin{abstract}
This study focuses on river bed fluctuation of the curved channel with channel width narrowing, where is located in the inlet of the old meandering river with $30(\mathrm{~m})$ width from straightened one with $80(\mathrm{~m})$ in the Kushiro Wetland. From field survey, in response to change in water and sediment discharges, significant streamwise variation in water flow width in the curved channel adjusts in order to establish the dynamic equilibrium. Along the outer bank of curved channel, the secular bed deposit beside the outer bank is increasing, and as a result, the main streamline flows into the old river along the inner bank as left bank. Moreover, this narrowing curved channel easily leads to overspill some flood water including rich suspended sediment and to deposit some fine sand near channel side flood plain. We intend to explain above significant bed variations by using movable bed experiments with the distorted model. As a result, we suggest, though qualitatively, that the existence of the sandbar upstream of the curved channel causes the autonomous specification of the flow path width in the curved channel with a narrowing width, and that this flow path is formed.
\end{abstract}

\section{Introduction}

The Kushiro Wetland, which is located in the east of the island Hokkaido as shown Figure1, is the largest one in Japan. There nurtures a rich diversity of plants and wildlife including Japanese cranes. However, this wetland has suffered from various human disturbance in particularly the most recent decade, and there the ecosystem considerably has been felt stress. In FY2002, nature restoration project of the Kushiro Wetland, which was registered under the Ramsar Convention, has been started as a pioneering case of nature restoration in Japan.

As part of nature restoration projects on the Kushiro River, Japan, a river reconstruction project was planned for the Kayanuma District along the edge of the Kushiro Wetland [1,2]. This project focused on river environment conservation and restoration, wetland restoration and sediment inflow control by returning the straightened river channel to its old meandering form in the way in much of the world [3 - 6]. As shown in Figure 2(a), the river was shifted to that channel in Feb. 2010, and the backfilling of the straightened channel were completed in FY2011. At the curved inlet (distance mark KP33.4) of the old meandering river, where the narrowed (30 meters) channel joins the wider ( 80 meters) straightened channel, the initial

*Corresponding author: h-haya@mail.kitami-it.ac.jp 
intention was to develop riverbed scouring along the outer bank of the curved channel. However, in actuality, sediment deposits and backfills along the outer bank autonomously and gradually narrowed the flow path width and directed flow along the inner bank of the curved channel, forming a flow path close to the old one. This is similar to the channel narrowing mechanism pointed out by Fujita [7] in channel segment 2-2 [8]: Sand-bed river, in which narrowing occurs along a new river bank due to a high-water channel formed by sediment deposited in a low-water channel whose width was increased by river improvement.

Channel overflow easily occurs at this inlet as shown in Figure 2(b) (overflow marked with a dashed line), and this plays a role in controlling the transport and deposition of suspended sediment during such flooding events. That is the main reason of this project to prevent of sediment inflow to the wetland inside. In order to maintain this role, it is necessary to identify the future fluctuations of the riverbed and the flow pathway of the channel inlet.

This study investigated the formation mechanism of the flow pathway formed in the narrowed channel inlet by clarifying the pathway's fluctuations according to field surveys and laboratory tests, which reproduced and verified the pathway fluctuation characteristics.

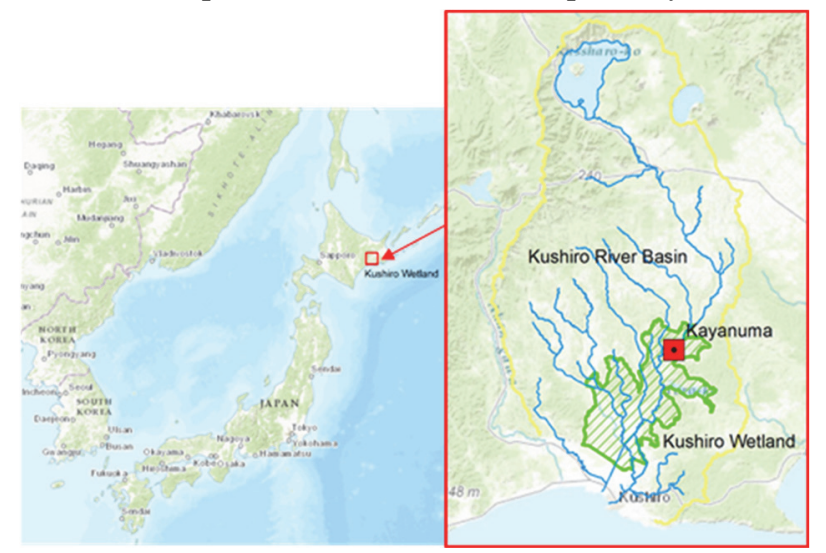

Fig. 1. Kushiro Wetland in the Kushiro River Basin.
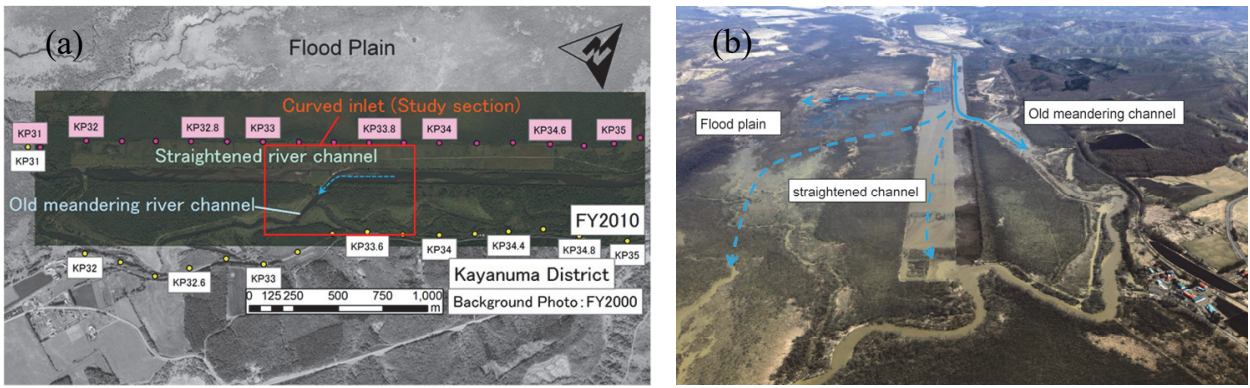

Fig. 2. River reconstruction project for the Kayanuma district. (a) plan figure. (b) overflow at the curved inlet.

\section{Old river reconstruction project for KAYANUMA district and status of the channel inlet}

In the Kayanuma District of Shibecha Town, located along the edge of the Kushiro Wetlands, the original Kushiro River meandered significantly and created a risk of overflow due to flooding; to prevent this, construction of a new, straightened channel was launched in FY1973 and completed in FY1980. This work lowered the ground-water level and reduced the frequency of flood overflows, while drying the area around the river and making it available as farm and pasture land. Although the wider channel reduced overflow frequency, 
the amount of sediment reaching downstream wetlands increased and this was considered a cause of drying in the central wetlands.

Under these circumstances, a reconstruction project was planned to reduce the impact on the wetlands and to conserve, recover, and reconstruct the original ecosystem of the river [2]; the project was started in 2006 and completed in Mar. 2011. The reconstruction project shifted the straightened river to the meandering old river at distance mark KP33.4 as shown in Figure 2(a) and redirected the flow back to the main river at KP32.0.

This study focused on the curved channel flowing into the old river (intersecting the outer bank at an angle of 50 degrees), as shown in Figure 2(a). We classified the straightened channel of the main river as channel segment 2-2 [8] with a width of 80 (meter, $\mathrm{m}$ ), bed slope of 1/1,900, and mean particle diameter of 2-4 (millimeter, $\mathrm{mm}$ ); the inlet of the old river has a width of $30(\mathrm{~m})$ and a bed slope of $1 / 400$.

\subsection{Survey method}

We conducted field surveys for the 200 (m) zone of the main river from KP33.4 to KP33.6 and for the $150(\mathrm{~m})$ zone of the old river from the construction survey points SP2200 to SP 2350, as shown in Figure 3.

For a land-area survey, we conducted a channel cross-sectional survey of the main river zone at $20(\mathrm{~m})$ intervals using a Total Station. As for the flow pathways of the main and old river channels, we used a rubber boat with an outboard motor, an onboard Acoustic Doppler Current Profiler (ADCP) (Stream-Pro manufactured by Teledyne RD Instruments), and a DGPS (Hemisphere A100) to check the route location; the boat cruised in zigzags to the left and right at right-angles to the flow as shown in Figure 3. The bed height $z$ (= water level $H$ - depth of water $h$ ) of a given point was determined by interpolating the water level $H$ of the given point based on the water level observed at multiple points. The bed height $z$ was determined by synchronizing the measurement locations and water levels obtained with the RTK-GPS to the ADCP data in surveys from Oct. 2013 and Oct. 2014.

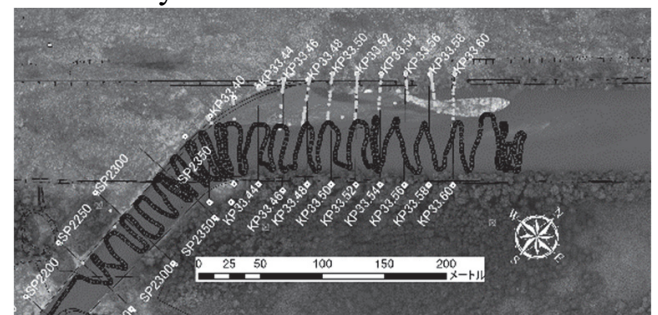

Fig. 3. Inlet of the curved channel showing boat survey tracks during the October 2014 survey.

\subsection{Fluctuations of bed height within the curved channel inlet}

Figure 4 with the background of Figure 3 show the fluctuations of bed height of the curved channel inlet from the period immediately after the shift to the old river to Oct. 2014.

Figure 4(a) shows that a long, thin, tongue-shaped sandbar with its back against the channel center near KP33.50 has formed downstream from the sandbar, which existed near KP33.64 before the shift. The flow separates between the inner left bank and this sandbar, and then moves into the old river as the outer bank of the curved channel serves to deflect the water. Extreme bed scouring was not seen in the bed of the outer bank. Note that the ordinary water level is approximately $10.5(\mathrm{~m})$ above sea level and that a contour line of this ground level is equivalent to the sandbar's leading edge.

Figure 4(b) shows the status approximately 2 years after the shift. Compared with Figure 4(a), the sandbar located near KP33.50 has moved downstream, while backfilling along the 
right bank, reaching the outer bank of the curved channel and blocking the former right-hand channel. On the other hand, the inner bank of the curved one shows a tendency to collect deposits. As a result, the flow path goes straight between the left bank and the sandbar front edge where it hits the outer bank of the curved channel as it goes around to the inner bank deposits, which has increased the shift of local scouring into the old river. At this point, the flow path width of approximately $40(\mathrm{~m})$ on the main river has gradually become closer to the old river's width of $30(\mathrm{~m})$.

Backfilling construction work for the main channel was completed in Mar. 2011; the height of the right bank was lowered to 10.5 (m) concurrently, to promote overflow onto the flood plain of the right bank. According to observations from the Water Level Station, Shibecha [9], located upstream at KP45.0, overflow at this location occurred when the water level $H$ of the observation station reached $H=19.2$ (m) or over. This occurred 10 to 20 times in 2011 . The $19.2(\mathrm{~m})$ water level at the observation station converts to an approximate flow rate $Q=50\left(\mathrm{~m}^{3} / \mathrm{s}\right.$, cubic meters per second), using the $H-Q$ formula. After taking into account the flow rate from the Osobetsu River and other tributaries, we estimated that the flow rate upon overflow is approximately $Q=100\left(\mathrm{~m}^{3} / \mathrm{s}\right)$. As the channel bankfull flow rate of the main straightened channel before shifting was $Q=150\left(\mathrm{~m}^{3} / \mathrm{s}\right)$ approximately, the frequency of overflow has increased by the lowering of the right bank's height.

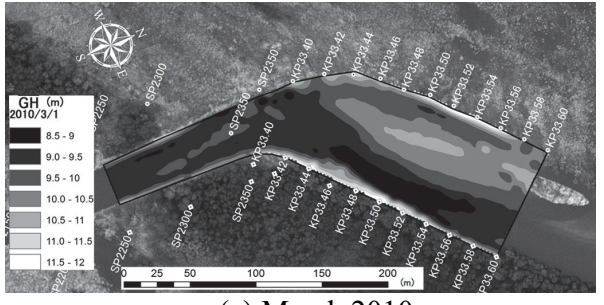

(a) March 2010

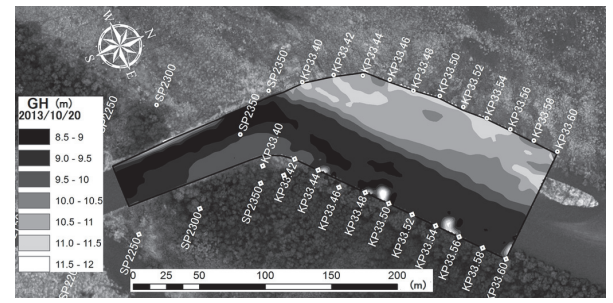

(c) October 2013

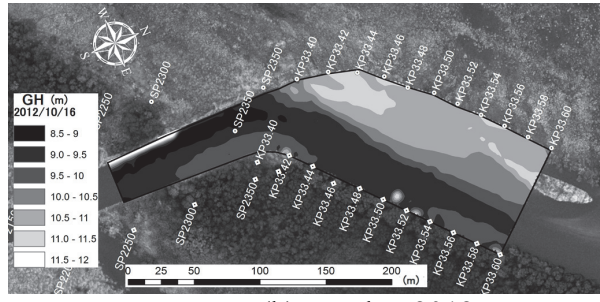

(b) October 2012

(data provided by the Kushiro DCD)

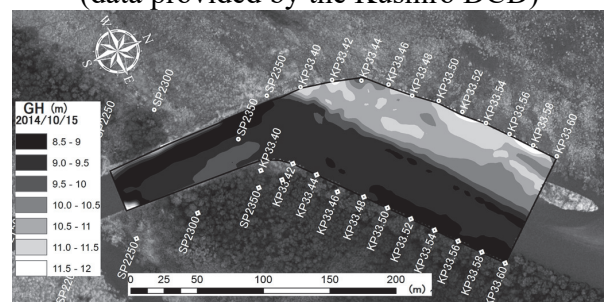

(d) October 201

Fig. 4. Plan view of the seasonal bed fluctuations at the inlet of the curved channel.

Figure 4(c) shows the status one year after these events. At the Shibecha St., a snowmelt flood of approximately $Q=250\left(\mathrm{~m}^{3} / \mathrm{s}\right)$ was observed on Apr. 7, 2013, and we estimate that the flow rate in the curved channel was over $Q=350\left(\mathrm{~m}^{3} / \mathrm{s}\right)$. In addition, on Sep. 16 of that year, $Q=300\left(\mathrm{~m}^{3} / \mathrm{s}\right)$ was observed at the station, and we estimate that the flow at this time reached $Q=500\left(\mathrm{~m}^{3} / \mathrm{s}\right)$. However, the bed height shown in Figure 4(c) has no significant change from the previous year and the pointbar on the right bank near KP33.60, which has existed before the channel shift, has maintained its shape while the flow bed height is slightly lowered. Although at this point the flow path has experienced significant flooding twice, it shows no significant change from the previous year, and the present width is similar to the mechanism pointed out by Fujita [7], in which the low-water channel width autonomously narrows. In other words, the mechanism in which a high-water channel forms on the channel's side bank, or the existing pointbar in this study, causes gradual deposits on the front of the right bank according to flow conditions and the high-water channel formed here 
autonomously narrows the pathway width, which also plays a role in the narrowing of the curved channel.

Figure 4(d) shows that the right bank pointbar on the right bank near KP33.60 has thick plant growth on its surface and there is no trace of flood impacts. The downstream deposits on the right bank's front have increased slightly from the previous year but the flow path width is almost the same as the previous year.

\section{Examination of flow path formation process using a distorted model experiment}

We used a hydraulic model experiment to reproduce and examine the bed fluctuations of the original river, by setting its original form to the curved channel of the old river reconstruction zone between KP33.40 and KP34.00 (main river zone) and between SP2200 and SP2350 (old river zone) at above the district; this model assumes overflow in order to examine the conditions for the formation of flow paths around the curved channel.

\subsection{Experimental overview}

We built the channel model by using insulation material on a variable-slope stage (with a total length of $12(\mathrm{~m})$ and a width of $1.2(\mathrm{~m})$ ). For laboratory convenience, the model channel meanders (Model) toward the right bank (as shown in Figure 5(a)) although the original river meanders (Prototype) toward the left bank. The prototype conditions, denoted by the subscript $P$, refer to the full-scale field conditions for which a hydraulic model, subscript $M$, is to be built in the laboratory. Model scales, subscript $R$, refer to the ratio of prototype to
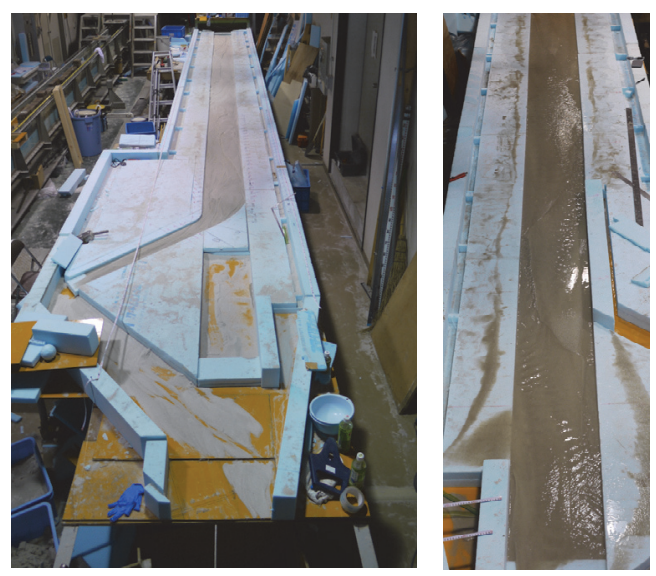
model conditions.

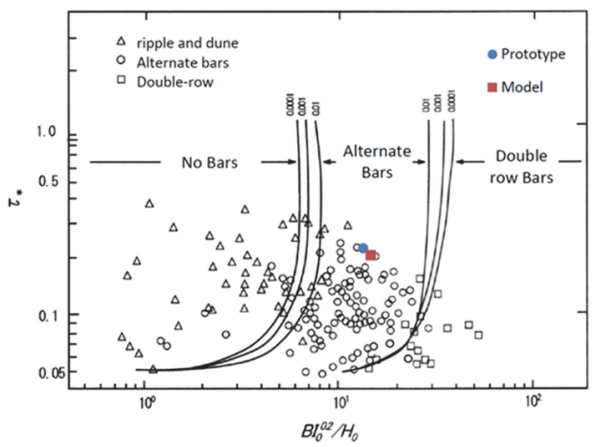

Fig. 6. Regime criteria on bars and braids by Kuroki and Kishi [8].

Fig. 5. Distorted model channel. (a) Curved channel (left). (b) Straight channel (right).

Because of laboratory space constraints, we adopted the distorted model channel experimental method [10], with a difference in the ratio of horizontal and vertical scale between the prototype and the model. This method focuses on the reproducibility of bed forms during the examination of moving riverbed fluctuations. Figure 6 shows the dimensionless parameters of the regime criteria on bars and braids as presented by Kuroki and Kishi [11]. The similarity conditions needed to match the Shields stress $\tau *$ on the vertical axis and $B I^{0.2} / h$ on the horizontal axis have been applied, where channel width: $B$, depth of flow: $h$, and bed slope: $I$. Although the similarity conditions for the flow regime (Froude Similarity Law) could not be satisfied, good results of reproduction can be obtained for the 
Table 1. Similarity conditions

\begin{tabular}{|l|l|l|c|c|}
\hline & channel width & grain diameter & $\begin{array}{l}\text { specific gravity } \\
\text { of sand in water }\end{array}$ & bed slope \\
\hline Prototype & $B_{P}=80(\mathrm{~m})$ & $d_{P}=2(\mathrm{~mm})$ & $S_{P}=1.0$ & $I_{P}=1 / 1893$ \\
\hline Model & $B_{M}=0.4(\mathrm{~m})$ & $d_{M}=0.59(\mathrm{~mm})$ & $S_{M}=1.0$ & $I_{M}=1 / 63.3$ \\
\hline Scale ratios & $B_{R}=200$ & $d_{R}=3.39$ & $s_{R}=1.0$ & $I_{R}=1 / 29.9$ \\
\hline
\end{tabular}

Distortion ratio $n=B_{R} / h_{R}=29.9$

riverbed fluctuations in previous research [12]. Due to laboratory space constrains, the horizontal scale ration of the channel width $B$ is set to $B_{R}=B_{P} / B_{M}=200$ and a grain diameter of $d_{M}=0.59(\mathrm{~mm})$ is used due to the requirement not to form sand ripples on the bed waves; this meets the similarity conditions shown in Table 1 . Moreover, the scale ratio of the flow rate $Q_{R}$ is as indicated in the following equation [10].

$$
Q_{M}=s_{R}^{-\frac{1}{6}} \cdot n^{\frac{19}{30}} \cdot B_{R}^{-\frac{5}{2}} \cdot Q_{P}
$$

\subsection{Experimental conditions}

As the prototype Manning's roughness $N_{P}$ of the Kushiro River low-water channel is set to $N_{P}=0.025$ [2], when the depth of flow with bankfull channel flow is set to $h_{P}=1.33(\mathrm{~m})$ according to the varied flow calculation, the bankfull flow rate of the main straight channel zone (from KP32.0 to KP35.0) is calculated as $Q_{P}=150\left(\mathrm{~m}^{3} / \mathrm{s}\right.$ ), and the model flow rate $Q_{M}$ is calculated as $Q_{M}=2.28\left(\times 10^{-3} \mathrm{~m}^{3} / \mathrm{s}\right)$ according to Equation (1). As the mean water depth of the moving bed channel $h_{M}$ with the grain diameter $d_{M}$ of $0.59(\mathrm{~mm})$ is calculated as $h_{M}=$ $1.2(\mathrm{~cm})$ according to the preliminary experiment, the Manning's roughness $N_{M}$ is backcalculated as $N_{M}=0.0137$. When plotting the hydraulic quantity of this prototype and the experiment model in the regime criteria of Figure 6, the two values do not present a perfect match, but they are located in the single-row bar regime, meaning that both of them form a single-row alternate bar. Figure 5(b) shows the preliminary experiment for the straight channel which provided the experiment model flow rate of $Q_{M}=2.28\left(\times 10^{-3} \mathrm{~m}^{3} / \mathrm{s}\right)$. This preliminary experiment was conducted to reproduce the bed conditions of the straight channel before the shift, and as shown in Figure 5(b), the formation of a single-row alternate bar was confirmed. Therefore, we conclude that the sandbar formed in the main straight channel is attributable to the single-row alternate bar.

Furthermore, the results of our field surveys point out that the existence of the pointbar on the right bank of the curved channel (KP33.60) affects the bed fluctuations of the curved channel, especially the determination of the width of the flow path. Accordingly, in this experiment, the behavior of the curved channel's flow path conforms to the condition that a pointbar exists on the right bank (left bank for this experiment) of the curved channel in the same manner as the actual river and provides the ordinary water flow rate where the height of pointbar top above sea level (required for the width-narrowing mechanism) is within the ordinary water level fluctuation width. After setting three cases of ordinary water flow rate $\left(Q_{P}=30,35,40\left(\mathrm{~m}^{3} / \mathrm{s}\right), Q_{M}=0.46,0.53,0.61\left(\times 10^{-3} \mathrm{~m}^{3} / \mathrm{s}\right)\right)$ to cover the top of the pointbar, water was passed at the stationary flow for two hours.

\subsection{Experimental results and reviews}

As the existence of the pointbar on the right bank of the curved channel (KP33.60) is important for considering the width-narrowing mechanism according to the field surveys, we examined the bed fluctuations of the curved channel and the width variations both when this pointdbar moves and when it does not move because it is covered by plants as in the field. 


\subsubsection{Pointbar movement}

In the experiment, after setting the initial condition under which the pointbar formed by providing the channel bankfull flow rate at the upstream end of the curved channel, the status after two hours of prototype flow rate of $Q_{P}=30\left(\mathrm{~m}^{3} / \mathrm{s}\right)$ is shown in Figure 7(a), while Figure 7(c) shows the bed height in millimeters from the channel bottom. As in the field surveys, the experiment reproduced the situation in which the outer bank of the curved channel has sand deposits and the water flows down along the inner bank to get close to the old river channel. After increasing the original model flow rate to $Q_{P}=35\left(\mathrm{~m}^{3} / \mathrm{s}\right)$, this status remains the same. Although the flow branches off to a pathway along the outer bank due to the increased depth of water, the main stream is located along the inner bank and the pathway along the inner bank forms within two hours to get close to the old river. After further increasing the original model flow rate to $Q_{P}=40\left(\mathrm{~m}^{3} / \mathrm{s}\right)$, branching and merging of the flow parts becomes active as shown in Figure 8(a). The sandbar of the initial bed is gradually eroded and scoured, and it almost disappears in two hours; then the full width of the curved channel becomes a flow path and flows into the old river. After continuously passing water, a pathway starts to form along the outer bank of the curved channel; accordingly, once the upstream sandbar disappears, a bed shape generally observed in the curved channel is formed. In other words, in order to form and maintain the pathway along the inner bank as found in the field, the existence of the upstream sandbar is essential.
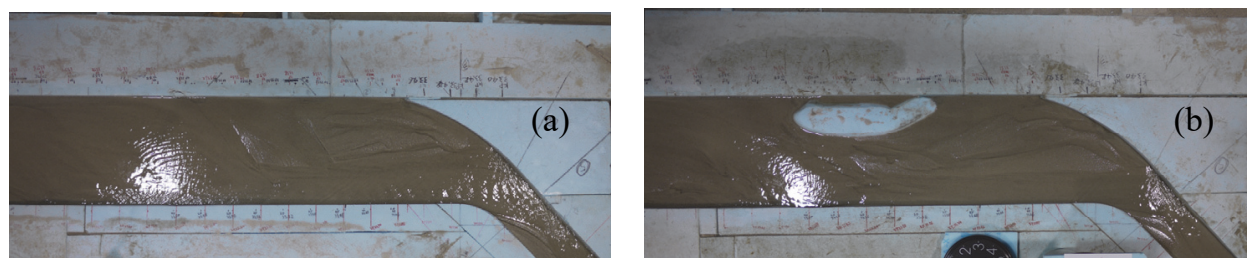

Flowing status: (a) in the case that the sandbar moves, (b) in the case that the sandbar does not move.
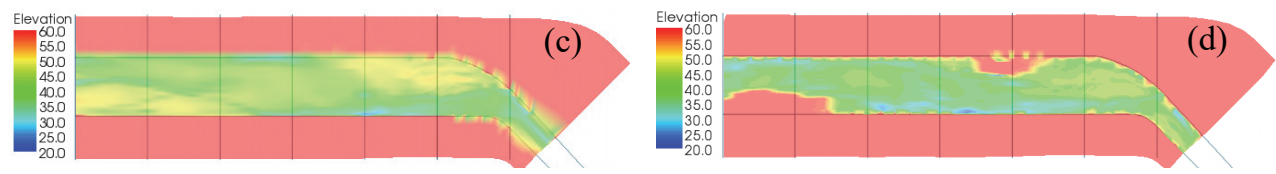

Bed height: (c) in the case that the sandbar moves, (d) in the case that the sandbar does not move.

Fig. 7. Distorted model with $Q_{M}=0.46 \mathrm{~m}^{3} / \mathrm{s}$ (prototype flow rate of $Q_{P}=30 \mathrm{~m}^{3} / \mathrm{s}$ ) after $t=120 \mathrm{~min}$.
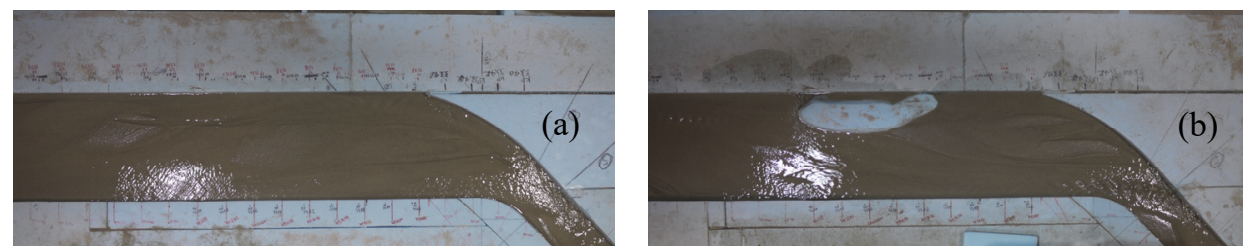

Flowing status: (a) in the case that the sandbar moves, (b) in the case that the sandbar does not move.
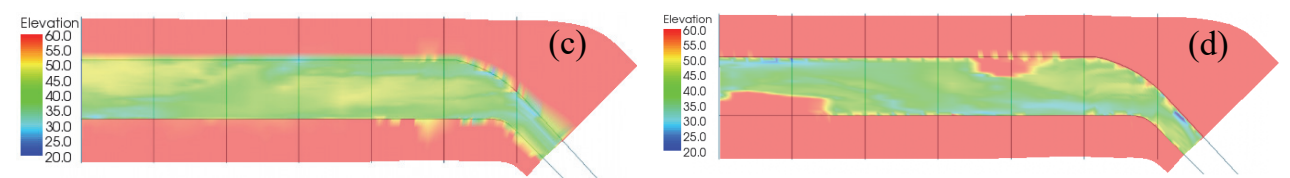

Bed height: (c) in the case that the sandbar moves, (d) in the case that the sandbar does not move.

Fig. 8. Distorted model with $Q_{M}=0.61 \mathrm{~m}^{3} / \mathrm{s}$ (prototype flow rate of $Q_{P}=40 \mathrm{~m}^{3} / \mathrm{s}$ ) after $t=120 \mathrm{~min}$.

\subsubsection{No pointbar movement (fixed in place)}


As the sandbar near KP33.60 in the field has thick plants on its surface and is fixed without being lushed by a medium-scale flood, we examined this scenario experimentally as well. Figure 7(b) and 7(d) show the results of this experiment, with a fixed sandbar near KP33.60 and the original model flow rate of $Q_{P}=30\left(\mathrm{~m}^{3} / \mathrm{s}\right)$. The flow is more concentrated due to the fixed sandbar along the inner bank, as compared to the case where the sandbar moves as described in the preceding section, and so the flow path width becomes narrower. With increasing flow rate, this path width expands to the fixed sandbar front as shown in Figure 8(b) and (d). In this way, sediment deposits on the immediate downstream of the fixed sandbar form additional deposits on the outer bank's front and a similar flow path as in the field. Therefore, although it is qualitative, we suggest that the existence of the sandbar upstream of the curved channel in the field specifies the formation of the downstream flow path and its width.

\section{Conclusions}

This study focused on channel bed fluctuations at the location where the Kushiro River was shifted to an old channel, as a part of post-evaluation monitoring of the old river reconstruction project in Kayanuma District completed in FY2010. In the inlet where the curved channel left the straight channel, we observed an autonomous flow path in which the straight channel width gradually narrows toward the old river channel width. This situation is similar to the autonomous width-narrowing mechanism referred to by Fujita [7]. We suggest, though qualitatively, that the existence of the sandbar upstream of the curved channel causes the autonomous specification of the flow path width in the curved channel with a narrowing width, and that this flow path is formed (according to the flow condition) by depositing sediment on the outer bank of the curved channel.

Whether or not this channel status will be maintained in the future is affected by the behavior of the sandbar located upstream of the curved channel. Currently, as the sediment on the downstream side of this sandbar is increasing, if further deposition occurs on the outer bank front of the curved channel and a bank which is not submerged in ordinary water is formed, as demonstrated in the width narrowing mechanism pointed out by Fujita[7], it will be necessary to continuously monitor to the status of the curved channel's inlet.

The authors are grateful to the River Foundation for the support in this study through their FY2013 and FY2016 River Fund.

\section{References}

1. Ministry of the Environment, Japan (http://kushiro.env.gr.jp/english/top_e.html, 2017)

2. Kushiro Wetland Nature Restoration Committee, Japan (http://www.hkd.mlit.go.jp/ks/tisui/qgmend0000003ppq.html, 2017) (in Japanese)

3. A. Brookes, River Conservation and Management, 337-352(John Wiley \& Sons, 1992)

4. The River Restoration Centre, Cranfield University, Manual of River Restoration Techniques, UK (http://www.therrc.co.uk/manual-river-restoration-techniques, 2017)

5. G. M. Kondolf, E. R. Micheli, Environmental Management, 19-1 1-15 (1995)

6. H.P. Wolfert, PhD Thesis of Utrecht University (Netherlands, 2001)

7. K. Fujita, 43rd Summer Seminar on Hydr. Eng. A JSCE A-7-1 (2007) (in Japanese)

8. K. Yamamoto, Report 168 1-66 (PWRI, 1984) (in Japanese)

9. MLITT, Japan, Water Information System (http://www1.river.go.jp/, 2017)

10. K. Uchijima, H. Hayakawa, J. JSCE, No. 479/II-25 71-79 (1993) (in Japanese)

11. M. Kuroki, T. Kishi, Proc. JSCE, 342, 87-96 (1984) (in Japanese)

12. H. Hayakawa, H. Miyamoto, Advances in River Eng. JSCE, 15 219-224 (2009) (in Japanese) 